Original Article

\title{
The effects of prone bridge exercise on trunk muscle thickness in chronic low back pain patients
}

\author{
Yong-Soo Kong, PhD, $\mathrm{PT}^{1)^{*}}$, Woo-Jin Lee, PhD, PT ${ }^{2)}$, Seol Park, PhD, $\mathrm{PT}^{1)}$, \\ GwON-UK JANG, MSc, PT $^{3)}$ \\ 1) Department of Physical Therapy, College of Medical Science, Catholic University of Daegu: 13-13 \\ Hayang-ro, Hayang-eup, Gyeongsan-si, Gyeongbuk 712-702, Republic of Korea \\ 2) Department of Physical Therapy, Gangneung Yeongdong College, Republic of Korea \\ 3) Department of Physical Therapy, General Graduate School, Catholic University of Daegu, Republic \\ of Korea
}

\begin{abstract}
Purpose] This study aimed to investigate the effects of prone bridge exercise on trunk muscle thickness. [Subjects and Methods] Thirty-seven chronic low back pain patients participated in this study. Each participant was randomly assigned to one of three exercise groups, namely, a prone bridge exercise group, supine bridge exercise on a Swiss ball group, and supine bridge exercise group. The thicknesses of the transverse abdominis (TrA), internal oblique (IO), and external oblique (EO) were measured using ultrasound. [Results] After eight weeks of training, the three groups showed significant increases in the thicknesses of the TrA, IO, and EO. Among the groups, TrA and IO showed significantly different muscle thicknesses. [Conclusion] The prone bridge exercise significantly affected the thicknesses of the TrA, IO, and EO unlike the supine bridge exercises. Based on the results of this study, the prone bridge exercise is a more effective method to improve trunk stability than conventional supine bridge exercises.
\end{abstract}

Key words: Bridge exercise, Muscle thickness, Chronic low back pain

(This article was submitted Feb. 2, 2015, and was accepted Mar. 24, 2015)

\section{INTRODUCTION}

Chronic low back pain (CLBP) is one of the common health problems in modern society, with $70-80 \%$ of the population having experienced back pain at least once in their lifetime ${ }^{1)}$. Picavet and Haxes ${ }^{2)}$ reported that $27 \%$ of the European population suffers from CLBP. People with CLBP show more muscle atrophy, especially of the lumbar deep muscles ${ }^{3,4)}$. Movement limited by low back pain causes morphological changes in the lumbar muscles that induce decreased muscle strength and endurance ${ }^{5)}$. Decreased muscle strength and endurance negatively affect lumbar stability and eventually cause functional limitations ${ }^{6}$.

Back pain in the lumbar area weakens the lumbar flexors and extensors ${ }^{6}$. Specifically, aside from the erector spinae and other abdominal muscles, the transverse abdominis of low back pain patients is weaker than that of healthy people ${ }^{7)}$. Back pain diminishes activity levels and results in muscle atrophy, with decreased muscle strength and a decreased sectional area of the muscles around the spine. As endurance and flexibility decrease due to these reasons, the

*Corresponding author. Yong-Soo Kong (E-mail: twinkong@ hanmail.net)

C2015 The Society of Physical Therapy Science. Published by IPEC Inc. This is an open-access article distributed under the terms of the Creative Commons Attribution Non-Commercial No Derivatives (by-ncnd) License $<$ http://creativecommons.org/licenses/by-nc-nd/3.0/> . range of back movement becomes limited ${ }^{8)}$.

Recent studies on and treatments for CLBP have been focused on increasing trunk stability to minimize recurrent episodes and maximize prevention. The main topics of these studies are trunk stability and the muscles involved in spine alignment and posture ${ }^{9)}$. Trunk muscles are co-activated to stabilize the trunk. Therefore, the co-activation of the trunk muscles is necessary to achieve trunk stability and to prevent and treat back pain ${ }^{10-12)}$. Many studies have suggested trunk stability exercises in different positions with or without an unstable platform device to strengthen the co-activation of trunk muscles ${ }^{13,14)}$. Bridge exercises are the most commonly used among the trunk stability exercises with different positions. Back pain patients are comfortable in assuming the bridge position and pain is reduced. Moreover, bridge exercises activate the superficial and deep trunk muscles at an appropriate ratio and strengthen the gluteus and lower leg muscles ${ }^{15)}$. In previous studies, prone bridge exercises activated the rectus abdominis, external oblique, and internal oblique more than supine bridge exercises ${ }^{16)}$, and prone bridge exercises on a Swiss ball activated the rectus abdominis and external oblique more than supine bridge exercises $^{17)}$

This study aimed to compare the effects of conventional supine bridge exercises and prone bridge exercises on trunk muscle thickness to determine which type of exercise is more efficient. 
Table 1. General characteristics of the subjects $(\mathrm{N}=37)$

\begin{tabular}{|c|c|c|c|c|c|}
\hline \multicolumn{2}{|c|}{ Characteristics } & $\begin{array}{c}\text { Total } \\
(\mathrm{n}=37)\end{array}$ & $\begin{array}{c}\text { Exercise } 1 \\
(\mathrm{n}=11)\end{array}$ & $\begin{array}{c}\text { Exercise } 2 \\
(\mathrm{n}=13)\end{array}$ & $\begin{array}{c}\text { Exercise } 3 \\
(\mathrm{n}=13)\end{array}$ \\
\hline \multicolumn{2}{|c|}{ Age (yr) } & $41.2 \pm 8.3$ & $39.4 \pm 7.7$ & $41.2 \pm 10.2$ & $42.9 \pm 7.1$ \\
\hline \multicolumn{2}{|c|}{ Height (cm) } & $163.8 \pm 5.9$ & $163.5 \pm 5.2$ & $163.2 \pm 6.5$ & $164.7 \pm 6.2$ \\
\hline \multicolumn{2}{|c|}{ Weight (kg) } & $61.5 \pm 7.6$ & $60.2 \pm 7.6$ & $59.4 \pm 6.7$ & $64.8 \pm 7.8$ \\
\hline \multirow{2}{*}{ Gender } & Male & $13(35.1)$ & $4(36.4)$ & $4(30.8)$ & $5(38.5)$ \\
\hline & Female & $24(64.9)$ & $7(63.6)$ & $9(69.2)$ & $8(61.5)$ \\
\hline
\end{tabular}

Mean \pm standard deviation

\section{SUBJECTS AND METHODS}

A total of 37 patients (13 males and 24 females) with CLBP participated in this study. For patients with chronic lumbar pain, basic physical therapy (H/P, ICT, and U/S) was performed in 40-minute sessions, three times a week, along with a bridge exercise. All the patients met the following inclusion criteria: older than 20 years old; more than 6 months since diagnosis of CLBP by X-ray, CT or MRI; no history of vestibular disease, neurologic disease, or spine surgery; no medicine for balance-related impairments; and able to do exercises. Their mean age, weight, and height were $41.2 \pm$ 8.3 years, $61.5 \pm 7.6 \mathrm{~kg}$, and $163.8 \pm 5.9 \mathrm{~cm}$, respectively (Table 1). The subjects understood the experimental purpose and methods and agreed voluntarily to participate in the study. All the participants read and signed an informed consent form approved by the local ethics committee of the Catholic University of Daegu.

All participants were randomly assigned to one of the three exercise groups (supine bridge exercise, supine bridge on a Swiss ball exercise, and prone bridge exercise). First, the participants in the supine bridge exercise group (Exercise 1) performed the bridge exercise in the supine position with their knee joints at 90 degrees, both arms spread at about 30 degrees, and both hands on the ground. They kept their head and neck in a straight position, with their eyes looking at the ceiling. Second, the participants in the supine bridge on a Swiss ball exercise group (Exercise 2) performed the same exercise as the Exercise 1 group, but they placed their legs on a Swiss ball. Lastly, the prone bridge exercise group (Exercise 3) performed the bridge exercise in a prone position with their elbows at 90 degrees, their bodies supported by their forearms and toes, their neck slightly extended, and their eyes looking toward the front. The subjects performed three sets of five reps for each exercise, which consisted of $30 \mathrm{~s}$ work and $30 \mathrm{~s}$ rest periods, on three days each week. The exercise programs were conducted for eight weeks at a designated training facility under the supervision of a trained physical therapist who ensured that each subject performed the exercises correctly.

To measure trunk muscle thickness, ultrasonography (Sonoace 6000 , Medison, Republic of Korea) with a frequency of $6-8.5 \mathrm{MHz}$ and a gain range of $20-80$ was conducted. Ultrasound images of the TrA, EO, and IO were obtained in B-mode with a $7.5 \mathrm{MHz}$ linear transducer. To minimize the difference between testers, one trained physical therapist participated as an examiner. During measurement, the subjects were in a supine position with a pillow under their knees. The ultrasound transducer was positioned at the intersection point between a line from the anterior superior iliac crest to the midaxillary area and a horizontal line passing through the belly button ${ }^{18-20)}$. All images were collected at the end of normal exhalation to control for the influence of respiration on the transverse abdominis ${ }^{21)}$. Image acquisition was performed three times, and the mean values were used for statistical analysis.

The data were analyzed using PASW Statistics 18 (SPSS Inc.). The Shapiro-Wilk test was used to verify the normal distribution of the variables. A paired t-test was used to determine the changes in the trunk muscle thicknesses before and after the exercises, and an analysis of covariance of muscle thickness before the exercise was used as the covariate. The Bonferroni post hoc test was also performed to identify the differences in the thicknesses of the trunk muscles among the various exercises. A p value of less than 0.05 was considered statistically significant.

\section{RESULTS}

The three exercise groups showed significant changes in TrA, EO, and IO thicknesses after exercise compared with the thicknesses before the exercises $(p<0.05)$. The thicknesses of the TrA and IO showed significant differences among the groups $(\mathrm{p}<0.05)$. Among the groups, the prone bridge exercise group showed the highest increase in muscles thicknesses of the TrA, IO, and EO, followed by the supine bridge exercise on a Swiss ball group and the supine bridge exercise group (Table 2).

\section{DISCUSSION}

A bridge exercise was selected to improve trunk muscle stability among patients with CLBP. To investigate an effective method of bridge exercise, the existing traditional bridge exercise was performed along with a prone bridge exercise, and the trunk muscles' thicknesses were subsequently measured. The purpose of trunk stability exercises is to protect the spine from recurrent micro-damage of muscles, pain due to spine instability, and degenerative changes in the spine ${ }^{12)}$. Muscle strengthening exercises are performed for the prevention and treatment of musculoskeletal diseases and for the improvement of exercise capacity ${ }^{14)}$. Generally, patients with low back pain show decreased muscle strength of the spine extensors and abdominals. Specifically, the strength of the $\operatorname{Tr} \mathrm{A}$ is weaker in individuals with low back pain than in those without ${ }^{22)}$. 
Table 2. Comparison of thickness of trunk muscles among groups (Unit: $\mathrm{mm}$ )

\begin{tabular}{|c|c|c|c|c|}
\hline Group & & Exercise 1 & Exercise 2 & Exercise 3 \\
\hline Variable & & Mean \pm SD & Mean \pm SD & Mean \pm SD \\
\hline \multirow{3}{*}{$\mathrm{IO}^{*}$} & Pre & $4.97 \pm 1.01$ & $5.14 \pm 1.60$ & $5.93 \pm 1.56$ \\
\hline & Post & $6.01 \pm 0.90$ & $6.28 \pm 1.53$ & $7.45 \pm 1.82$ \\
\hline & change & $-1.03 \pm 0.35^{3^{* *}}$ & $-1.14 \pm 0.49^{3^{* *}}$ & $-1.52 \pm 0.70^{1,2^{* *}}$ \\
\hline \multirow{3}{*}{$\operatorname{Tr} \mathrm{A}^{* *}$} & Pre & $2.62 \pm 0.48$ & $2.53 \pm 0.67$ & $3.30 \pm 0.57$ \\
\hline & Post & $2.93 \pm 0.48$ & $3.07 \pm 0.72$ & $4.20 \pm 0.75$ \\
\hline & change & $-0.30 \pm 0.12^{2,3^{* *}}$ & $-0.54 \pm 0.18^{1,3^{* *}}$ & $-0.89 \pm 0.39^{1,2^{* *}}$ \\
\hline \multirow{3}{*}{ EO } & Pre & $3.77 \pm 1.08$ & $3.57 \pm 1.06$ & $4.04 \pm 0.66$ \\
\hline & Post & $4.71 \pm 1.02$ & $4.57 \pm 1.00$ & $5.22 \pm 0.72$ \\
\hline & change & $-0.94 \pm 0.86^{*}$ & $-0.99 \pm 0.39^{* *}$ & $-1.17 \pm 0.65^{* *}$ \\
\hline
\end{tabular}

$* \mathrm{p}<0.05, * * \mathrm{p}<0.001$

IO: internal oblique, TrA: transverse abdominis, EO: external oblique

${ }^{1}$ significantly different compared with exercise 1

2 significantly different compared with exercise 2

${ }^{3}$ significantly different compared with exercise 3

The strength of the deep muscles around the lumbar spine in patients with low back pain is also unbalanced. Patients with low back pain demonstrate decreased proprioception, which causes position sense impairments and eventually spine instability. As a result, patients with low back pain experience recurrent back pain ${ }^{23}$. For this reason, many studies have been conducted to improve deep muscle strength. However, to date, minimal research has been conducted on direct measurement of deep muscles. Ultrasound can be used to show deep muscle thickness even when muscles contract for certain movements ${ }^{24,25)}$. The reliability of ultrasound was proved in previous studies ${ }^{26)}$.

This study used ultrasound to measure the effect of eight weeks of bridge exercise on muscle thicknesses. The results show that the thicknesses of the TrA, IO, and EO increased significantly after prone bridge exercise, followed by supine bridge exercise on a Swiss ball and then supine bridge exercise. Interestingly, the muscle thicknesses of the TrA, IO, and EO after prone bridge exercise increased significantly more than after conventional bridge exercise. With prone bridge exercise, the deep muscles, TrA, and IO are activated more to stabilize the trunk and make it thicker. Increased muscle thickness means increased muscle activation. Subjects with low back pain are known to have postural control impairments; therefore, a postural control program should be considered part of their rehabilitation plan ${ }^{27}$. Trunk stability plays an important role in postural control, and the functions of the TrA, IO, and EO are crucial for trunk stability ${ }^{28}$.

In this study, prone bridge exercise significantly increased the thicknesses of these muscles compared with other bridge exercises. Therefore, prone bridge exercise could be suggested as a method of improving postural control for patients with back pain. The reasons for the significant improvement of muscle thicknesses with prone bridge exercise compared with the other bridge exercises can be suggested biomechanically and physiologically. Biomechanically, the prone position has a smaller base of support compared with the other bridge exercises. Therefore, to maintain postural control, increased muscle activation is required ${ }^{16)}$. Moreover, the prone bridge exercise raises the individual to resist gravity during the process of the spinal flexion pattern. That is, as the elbows and toes touch the ground, the trunk muscles are required to counteract gravity through co-contraction. Physiologically, the prone bridge position, with the upper and lower extremities acting as a bridge, activates the muscles placed transversely first (e.g., the $\operatorname{TrA}$ and then the IO and EO) for trunk stability. This is why increased muscle activation is induced.

The subjects in this study reported difficulty in lifting their pelvis during supine bridge exercises when pain worsened. However, they reported easiness in assuming the prone bridge posture compared with the supine bridge postures. Accordingly, patients with acute back pain, not only those with CLBP, can also perform the prone bridge exercise safely. In conclusion, prone bridge exercise is the more efficient for improving trunk stability and increasing trunk muscle thicknesses compared with the supine bridge exercises in patients with CLBP. A limitation of this study is that we only measured the thicknesses of the IO, EO, and TrA muscles. As the study measured only muscle thickness, the study results are hard to generalize. Moreover, bridge exercises mobilize many muscles in the trunk and extremities, and other factors can affect muscle thickness. Hence, further studies will be required to examine muscle activity with electromyography.

\section{REFERENCES}

1) Itoh $\mathrm{K}$, Itoh $\mathrm{S}$, Katsumi $\mathrm{Y}$, et al.: A pilot study on using acupuncture and transcutaneous electrical nerve stimulation to treat chronic non-specific low back pain. Complement Ther Clin Pract, 2009, 15: 22-25. [Medline] [CrossRef]

2) Picavet HS, Hazes JM: Prevalence of self reported musculoskeletal diseases is high. Ann Rheum Dis, 2003, 62: 644-650. [Medline] [CrossRef]

3) Hides JA, Stokes MJ, Saide M, et al.: Evidence of lumbar multifidus muscle wasting ipsilateral to symptoms in patients with acute/subacute low back pain. Spine, 1994, 19: 165-172. [Medline] [CrossRef]

4) Tertti MO, Salminen JJ, Paajanen HE, et al.: Low-back pain and disk degeneration in children: a case-control MR imaging study. Radiology, 1991, 180: 503-507. [Medline] [CrossRef] 
5) Stokes GM, Milner AD, Upton CJ: Is thoraco-abdominal phase relationship an indicator of sleep state? Eur J Pediatr, 1992, 151: 526-527. [Medline] [CrossRef]

6) Johannsen F, Remvig L, Kryger P, et al.: Exercises for chronic low back pain: a clinical trial. J Orthop Sports Phys Ther, 1995, 22: 52-59. [Medline] [CrossRef]

7) Hodges PW, Richardson CA: Inefficient muscular stabilization of the lumbar spine associated with low back pain. A motor control evaluation of transversus abdominis. Spine, 1996, 21: 2640-2650. [Medline] [CrossRef]

8) Yoshihara K, Shirai Y, Nakayama Y, et al.: Histochemical changes in the multifidus muscle in patients with lumbar intervertebral disc herniation. Spine, 2001, 26: 622-626. [Medline] [CrossRef]

9) Norris CM: Functional load abdominal training: part 1. J Bodyw Mov Ther, 1999, 3: 150-158. [CrossRef]

10) Lehman GJ, Hoda W, Oliver S: Trunk muscle activity during bridging exercises on and off a Swiss ball. Chiropr Osteopat, 2005, 13: 14. [Medline] [CrossRef]

11) Marshall PW, Murphy BA: Core stability exercises on and off a Swiss ball Arch Phys Med Rehabil, 2005, 86: 242-249. [Medline] [CrossRef]

12) Stevens VK, Bouche KG, Mahieu NN, et al.: Trunk muscle activity in healthy subjects during bridging stabilization exercises. BMC Musculoskelet Disord, 2006, 7: 75. [Medline] [CrossRef]

13) Haynes W: Core stability and the unstable platform device. J Bodyw Mov Ther, 2004, 8: 88-103. [CrossRef]

14) Akuthota V, Nadler SF: Core strengthening. Arch Phys Med Rehabil, 2004, 85: S86-S92. [Medline] [CrossRef]

15) Kisner C, Colby LA: Therapeutic Exercise: Foundations and Techniques. 4th ed. Philadelphia: FA Davis, 2002

16) Kong YS, Cho YH, Park JW: Changes in the activities of the trunk muscles in different kinds of bridging exercises. J Phys Ther Sci, 2013, 25: 16091612. [Medline] [CrossRef]

17) Jung JH, Yu JH, Kang HK: Differences in trunk muscle activities and ratios between unstable supine and prone bridging exercises in individuals with low back pain. J Phys Ther Sci, 2012, 24: 889-892. [CrossRef]

18) Whittaker JL: Ultrasound imaging of the lateral abdominal wall muscles in individuals with lumbopelvic pain and signs of concurrent hypocapnia. Man Ther, 2008, 13: 404-410. [Medline] [CrossRef]

19) McMeeken JM, Beith ID, Newham DJ, et al.: The relationship between EMG and change in thickness of transversus abdominis. Clin Biomech (Bristol, Avon), 2004, 19: 337-342. [Medline] [CrossRef]

20) Koppenhaver SL, Hebert JJ, Fritz JM, et al.: Reliability of rehabilitative ultrasound imaging of the transversus abdominis and lumbar multifidus muscles. Arch Phys Med Rehabil, 2009, 90: 87-94. [Medline] [CrossRef]

21) Hodges PW, Gandevia SC: Activation of the human diaphragm during a repetitive postural task. J Physiol, 2000, 522: 165-175. [Medline] [CrossRef]

22) Hodges PW: Is there a role for transversus abdominis in lumbo-pelvic stability? Man Ther, 1999, 4: 74-86. [Medline] [CrossRef]

23) O'Sullivan PB, Burnett A, Floyd AN, et al.: Lumbar repositioning deficit in a specific low back pain population. Spine, 2003, 28: 1074-1079. [Medline] [CrossRef]

24) Rankin G, Stokes M, Newham DJ: Size and shape of the posterior neck muscles measured by ultrasound imaging: normal values in males and females of different ages. Man Ther, 2005, 10: 108-115. [Medline] [CrossRef]

25) Watanabe K, Miyamoto K, Masuda T, et al.: Use of ultrasonography to evaluate thickness of the erector spinae muscle in maximum flexion and extension of the lumbar spine. Spine, 2004, 29: 1472-1477. [Medline] [CrossRef]

26) Kristjansson E: Reliability of ultrasonography for the cervical multifidus muscle in asymptomatic and symptomatic subjects. Man Ther, 2004, 9: 83-88. [Medline] [CrossRef]

27) Alexander KM, LaPier TL: Differences in static balance and weight distribution between normal subjects and subjects with chronic unilateral low back pain. J Orthop Sports Phys Ther, 1998, 28: 378-383. [Medline] [CrossRef]

28) Stevens VK, Coorevits PL, Bouche KG, et al.: The influence of specific training on trunk muscle recruitment patterns in healthy subjects during stabilization exercises. Man Ther, 2007, 12: 271-279. [Medline] [CrossRef] 